\title{
Current perspectives on the role of bioresorbable scaffolds in the management of coronary artery disease
}

\author{
Artur Dziewierz ${ }^{1}$, Dariusz Dudek² \\ $1^{1} 2^{\text {nd }}$ Department of Cardiology, Institute of Cardiology, Jagiellonian University Medical College, Krakow, Poland \\ ${ }^{2}$ Department of Interventional Cardiology, Institute of Cardiology, Jagiellonian University Medical College, Krakow, Poland
}

\begin{abstract}
A bstract
New-generation drug-eluting stents are recommended as the default option in all clinical conditions and lesion subsets in patients undergoing percutaneous coronary intervention ( $\mathrm{PCl}$ ). On the other hand, despite achieving very good results in the rate of restenosis, permanent delivery of a metallic platform is affected by several drawbacks, such as caging of the vessel, side branch jailing, impairment of vasomotion, and the impossibility of lumen enlargement. Also, the presence of residual foreign material may increase the risk of late and very late stent thrombosis and support the need for long-term dual antiplatelet therapy after PCl. These pending limitations of metallic stents can be addressed by the implantation of bioresorbable scaffolds (BRSs). At present, there are numerous devices available for preclinical or clinical evaluation. This review discusses the evidence for BRS in the management of patients with coronary artery disease.
\end{abstract}

Key words: bioresorbable scaffolds, scaffold thrombosis, stents, percutaneous coronary interventions, outcomes

Kardiol Pol 2018; 76, 7: 1043-1054

\section{INTRODUCTION}

Over 40 years have passed since Andreas Gruentzig performed the first successful percutaneous coronary angioplasty of the proximal left anterior descending artery. Since then, rapid development in percutaneous interventional techniques has been observed, including the introduction of the bare-metal stent (BMS) and the drug-eluting stent (DES). Importantly, it has been shown that stent implantation during percutaneous coronary intervention $(\mathrm{PCl})$ reduces the risk of acute complications of $\mathrm{PCl}$, as compared to balloon angioplasty alone [1]. Also, it reduces the risk of target-lesion (TLR) and target-vessel revascularisation (TVR), especially with the use of DES [2, 3]. New-generation DESs have become the epitome of clinical performance, and their use is recommended in almost every clinical and angiographic scenario in patients with coronary artery disease (CAD) [4-7]. However, despite achieving very good results in the rate of TLR/TVR with DES, permanent delivery of a metallic platform is affected by several drawbacks, such as caging of the vessel, side branch jailing, impairment of vasomotion, and the impossibility of lumen enlargement
[8-10]. Also, the presence of residual foreign material may increase the risk of late and very late stent thrombosis and support the need for long-term dual antiplatelet therapy (DAPT) after PCI [8-10]. Trapping the coronary artery in a metallic cage, especially the mid-portion of the left anterior descending coronary artery, may exclude the possibility of future graft anastomosis in case of the need for coronary artery bypass grafting. These pending limitations of metallic stents can be addressed by the implantation of bioresorbable scaffolds (BRSs) [8-10]. Over the last two decades, considerable effort has been made to develop new fully bioresorbable devices. At present, there are numerous devices available for preclinical or clinical evaluation [8, 10-13]. This review discusses the evidence for BRS in the management of patients with CAD.

\section{BIORESORBABLE SCAFFOLDS: CONCEPT AND AVAILABLE DEVICES}

Bioresorbable scaffolds, also known as fully bioresorbable stents, were designed to provide temporary mechanical scaffolding within months to years after implantation and subse- 


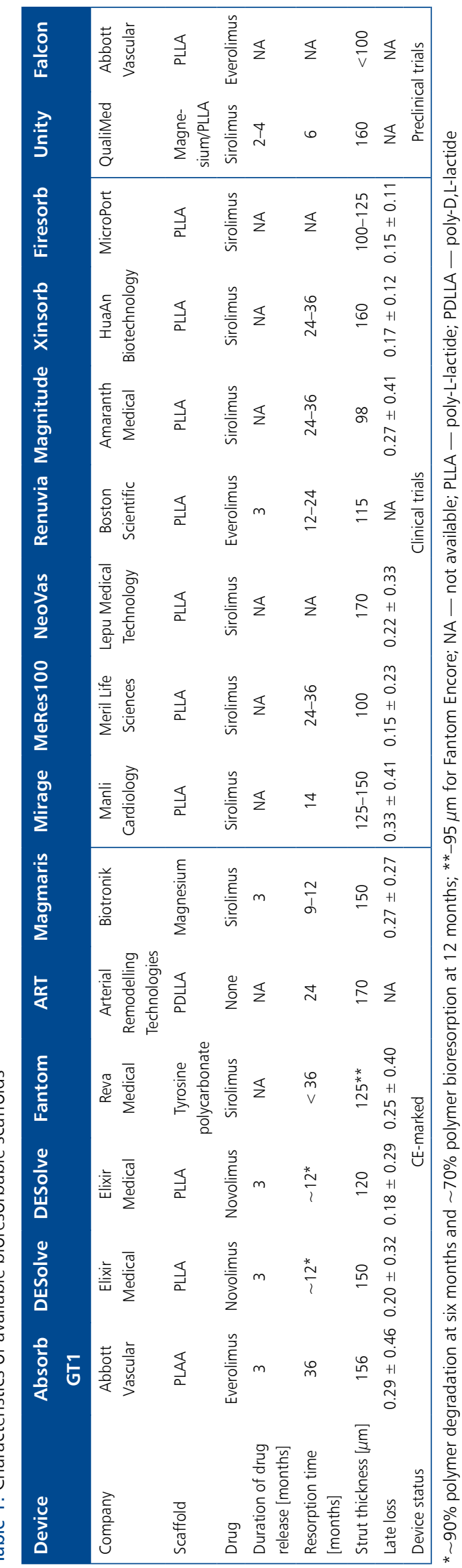

quently undergo bioresorption. Regarding the composition of the backbone, BRS may be identified as polymeric (composed of polylactic acid or related compounds) or metallic (composed of magnesium alloy) [12]. Apart from the backbone, they typically consist of a biodegradable polymer matrix and an antiproliferative drug. The acute performance of a scaffold should mimic that of DES (good deliverability, minimum acute recoil). The resorption process of BRS progresses gradually, mainly due to hydrolysis; thus, minimal or no inflammation can be observed. Complete bioresorption of BRS results in vessel uncaging and was believed to be associated with subsequent restoration of vasomotion and endothelial function (vascular restoration therapy) [9]. Another important part of this concept is restoration of low thrombogenic milieu which may lead to reduced risk of very late in-scaffold thrombosis and no need of prolonged DAPT. In addition, a better control of vascular healing followed by a reduced risk of neoatherosclerosis after BRS was expected.

So far, five BRSs have received the approval of the Communauté Européenne (CE): the Absorb bioresorbable vascular scaffold 1.1 (Abbott Vascular, CA, USA), the DESolve scaffold (Elixir Medical, CA, USA), the Fantom scaffold (Reva Medical, CA, USA), the ART (Arterial Remodelling Technologies, France), and the Magmaris (Biotronik, Germany). All of them save the last one are polymeric BRSs. The key features of these BRSs are summarised in Table 1.

\section{ABSORB BIORESORBABLE SCAFFOLD}

The Absorb bioresorbable vascular scaffold consists of a polymer backbone of poly-L-lactide (PLLA) coated with poly-D,L-lactide (PDLLA), which contains and controls the release of everolimus (Fig. 1A). The Absorb received CE mark approval in January 2011. However, due to some safety concerns, discussed above, since September 2017 it has no longer been available on the European market [14].

Initial studies showed late lumen enlargement as well as restoration of vasomotion and endothelial function at two years after the Absorb implantation [15]. In this initial, highly selected cohort of patients excellent clinical performance with no events of very late device thrombosis was confirmed. A case example of an Absorb implantation is depicted in Figure 2. Also, several registries have confirmed the feasibility of the Absorb implantation for so-called "off-label" indications [16, 17], i.e. acute coronary syndromes [18-20], bifurcations [21], saphenous vein grafts [22], chronic total occlusions, etc. However, results of the European multicentre GHOST-EU registry suggest an elevated risk of definite or probable device thrombosis in patients treated with the Absorb in the "real-world" setting ( $1.5 \%$ at 30 days and $2.1 \%$ at six months) [23].

Several randomised studies and their meta-analyses assessed the clinical performance of the device (Figs. 3, 4). The largest of them was the ABSORB III study, which enrolled 2008 patients with stable or unstable angina, who were randomly assigned in a 2:1 ratio to receive the Absorb 


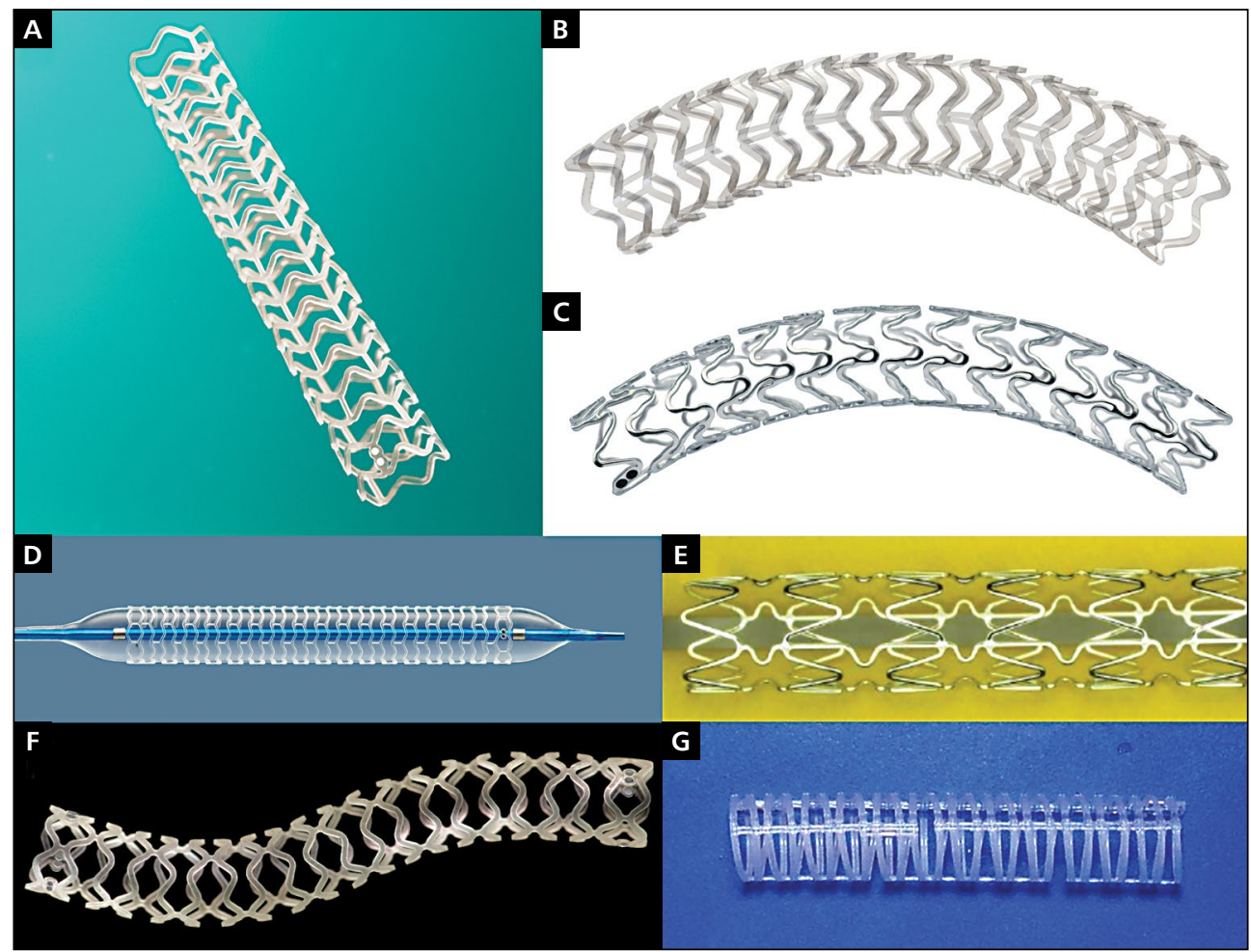

Figure 1. Examples of available bioresorbable scaffold technologies: A. Absorb (Abbott Vascular, CA, USA); B. Fantom (Reva Medical, CA, USA); C. Magmaris (Biotronik, Germany); D. Fantom (Reva Medical, CA, USA); E. Unity (QualiMed, Germany); F. MeRes100 (Meril Life Sciences, India); G. Mirage (Manli Cardiology, Singapore). Reproduced with permission from each company
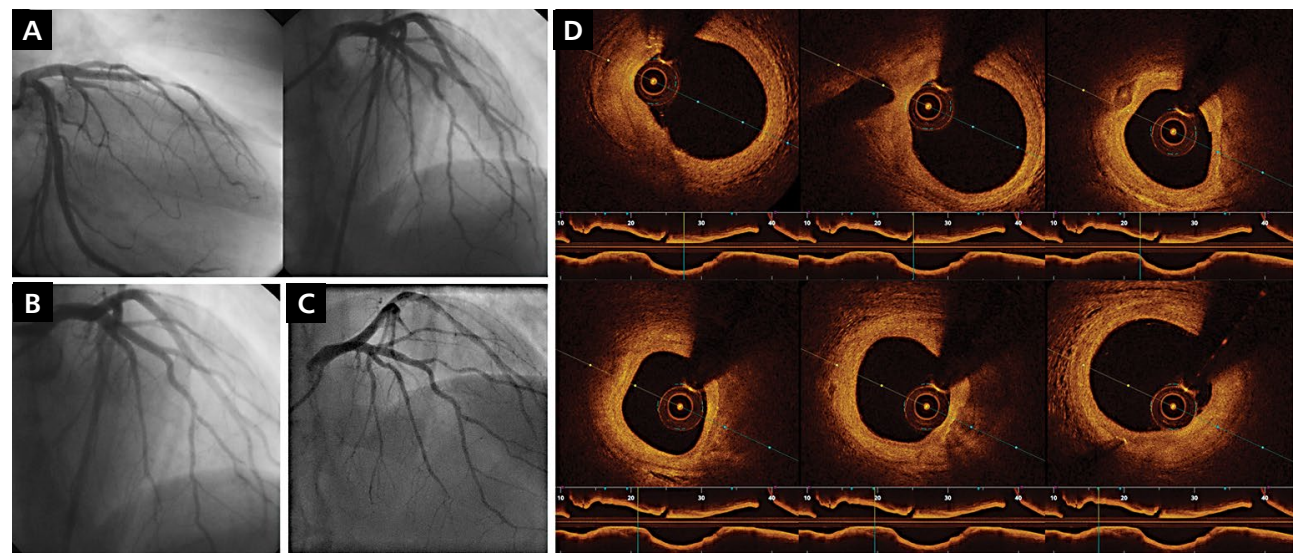

Figure 2. A case example of a 60 -year-old male patient with stable angina treated with Absorb scaffold (the ABSORB study); A. Baseline angiography with $80 \%$ stenosis of the left anterior descending artery; B. Final angiography after successful implantation of the Absorb scaffold $3.0 \times 12 \mathrm{~mm}$ up to $14 \mathrm{~atm}$ and postdilatation with non-compliant balloon $3.0 \times 6 \mathrm{~mm}$ up to 16 atm; C. Eleven-year control angiography before planned aortic valve surgery with a maintained optimal result of scaffold implantation; D. Eleven-year control optical coherence tomography with a complete dissolution of the scaffold and so-called "golden-tube" picture (remodelling with lumen enlargement, vessel wall thinning, and pseudo-atheroregression caused by vascular reparative therapy with a bioresorbable scaffold)

(1322 patients) or an everolimus-eluting cobalt-chromium (Xience) stent (686 patients) [24]. The primary endpoint was the target-lesion failure (TLF) defined as a composite of cardiac death, target-vessel myocardial infarction (MI), or ischaemia-driven TLR at one year, and it was tested for both non-inferiority and superiority. At one year, the rate of TLF was higher in patients treated with the Absorb than with the Xience $(7.8 \%$ vs. $6.1 \% ; p=0.007$ for non-inferiority and 


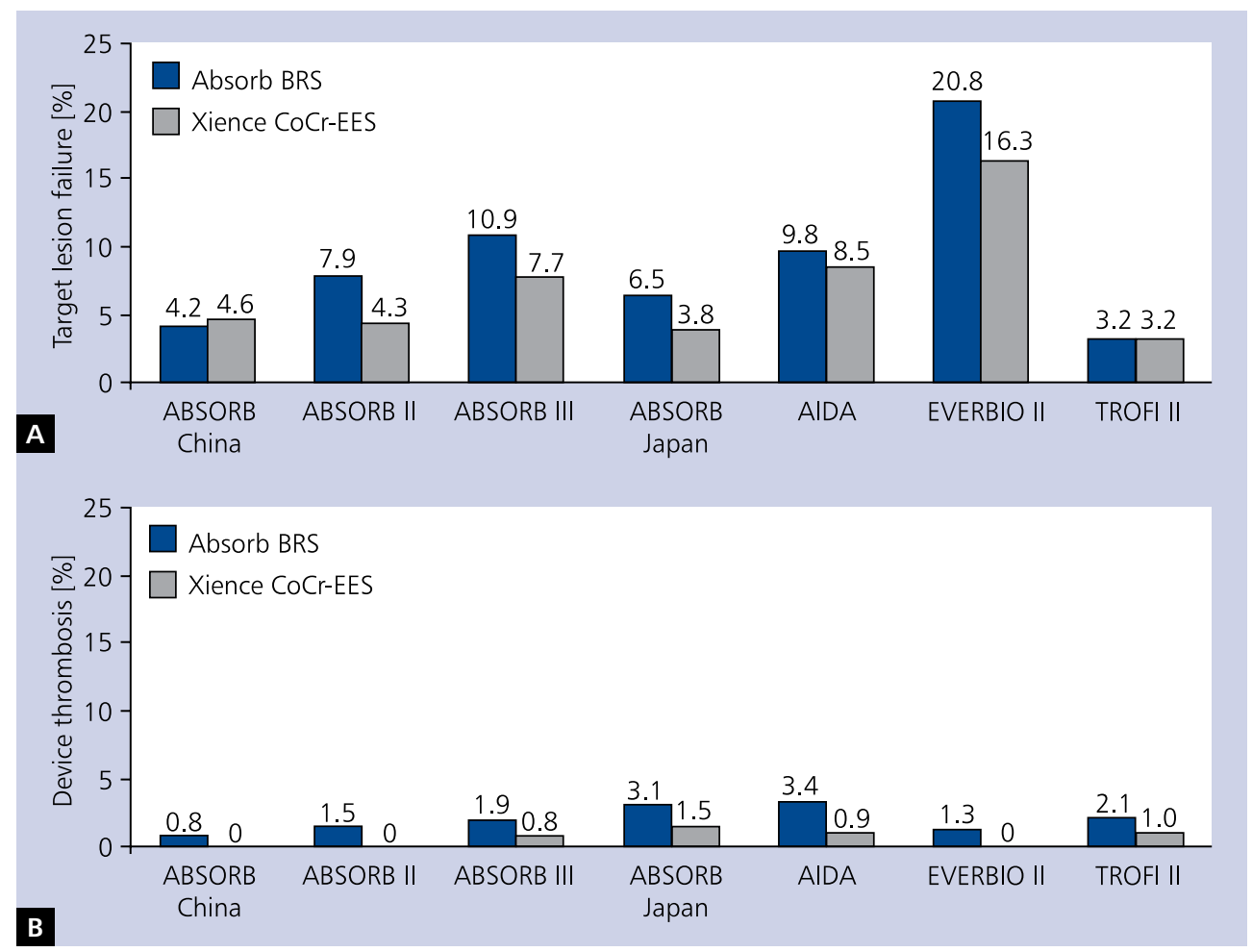

Figure 3. Two-year target lesion failure $(\mathrm{A})$ and definite/probable device thrombosis $(\mathrm{B})$ in major randomised clinical trials with the Absorb [29]; BRS — bioresorbable scaffold; CoCr-EES — cobalt-chromium-everolimus-eluting stent

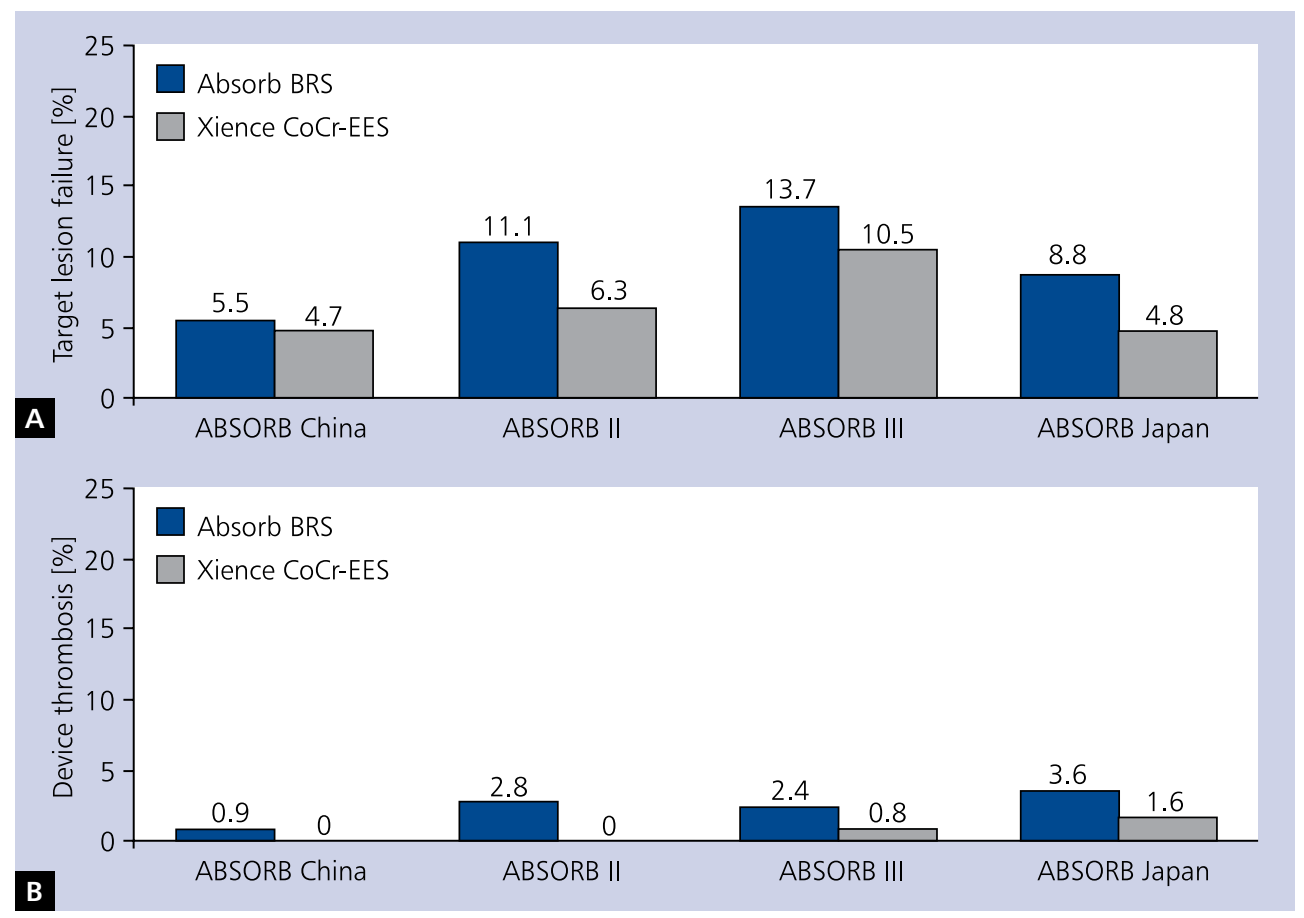

Figure 4. Three-year target lesion failure (A) and definite/probable device thrombosis (B) in major randomised clinical trials with the Absorb [30]; BRS — bioresorbable scaffold; CoCr-EES — cobalt-chromium-everolimus-eluting stent 


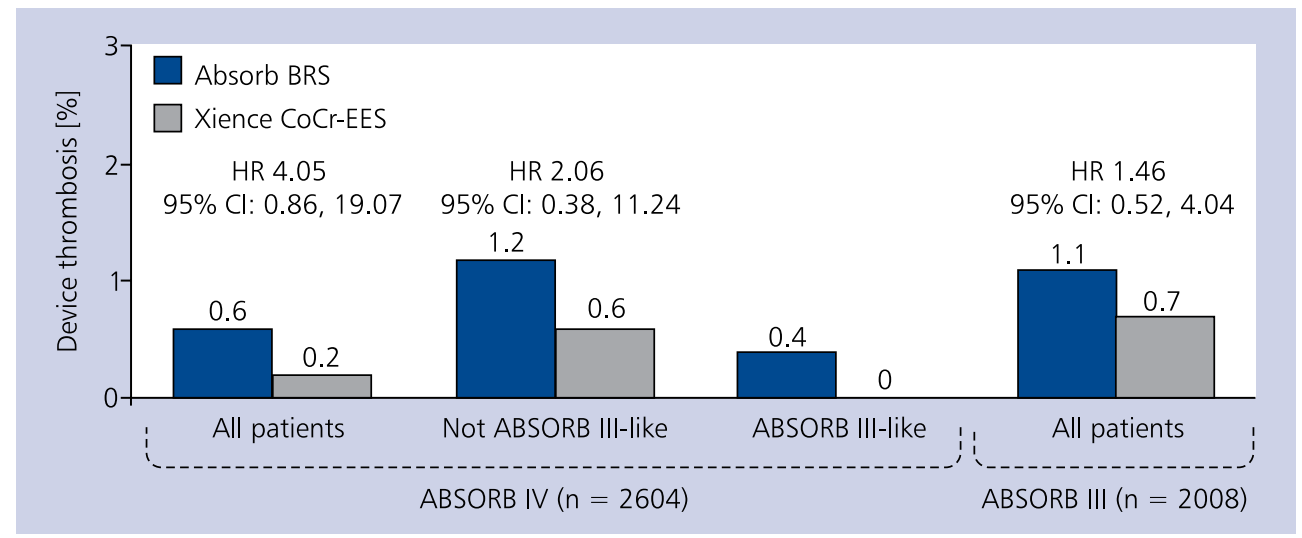

Figure 5. Thirty-day definite/probable device thrombosis in ABSORB III and IV studies. A total of 1918 (73.7\%) patients enrolled in ABSORB IV fulfilled ABSORB III study criteria - "ABSORB III-like", and 686 did not (20.8\% acute myocardial infarction, 0.5\% three lesions treated, 2.1\% thrombus) [Stone, TCT 2017]; BRS — bioresorbable scaffold; CI — confidence interval; CoCr-EES — cobalt-chromium-everolimus-eluting stent; HR — hazard ratio

$p=0.16$ for superiority). Also, the rate of device thrombosis was numerically higher (two times) for the Absorb $(1.5 \%$ vs. $0.7 \% ; p=0.13$ ). Importantly, no differences in the rate of cardiac death, target-vessel MI, and ischaemia-driven TLR were observed. Interestingly, the difference in the rate of TLF was no longer significant at three years $(13.4 \%$ vs. $10.4 \%$; $\mathrm{p}=0.06)$. However, the rates of target-vessel $\mathrm{MI}(8.6 \%$ vs. $5.9 \% ; p=0.03)$ and device thrombosis $(2.3 \%$ vs. $0.7 \%$; $p=0.01$ ) were higher for the Absorb [25]. Importantly, for patients treated with the Absorb, the treatment of very small vessels (reference vessel diameter [RVD] $<2.25 \mathrm{~mm}$ ) was identified as an independent predictor of three-year TLF and scaffold thrombosis.

The second large randomised study was the AIDA, which enrolled 1845 patients undergoing $\mathrm{PCl}$, who received either the Absorb (924 patients) or a metallic stent (Xience, 921 patients) [26]. In the study, more than half of the patients had an acute coronary syndrome. Similarly to the ABSORB III study, the primary endpoint was target-vessel failure (TVF; a composite of cardiac death, target-vessel MI, or TVR). Due to safety concerns, the data and safety monitoring board recommended early reporting of the study results. At two years the rates of TVF $(11.7 \%$ vs. $10.7 \% ; p=0.43)$ and cardiac death $(2.0 \%$ vs. $2.7 \%)$ were comparable in patients treated with the Absorb and the Xience stent. However, the risk of definite or probable device thrombosis after two years was almost four times higher for the Absorb (3.5\% vs. 0.9\%; $\mathrm{p}<0.001$ ) [26].

Another study is ABSORB IV, from which initial, 30-day results were recently presented [Stone, TCT 2017]. In this study, 2604 patients were randomly assigned to either the Absorb $(n=1296)$ or the Xience $(n=1308)$ stent. In contrast to previous ABSORB studies, an expanded patient population including patients with acute coronary syndromes was enrolled. In addition, avoidance of small vessels was man- dated, and optimal implantation technique with aggressive predilatation and routine high-pressure postdilatation were encouraged. At 30 days, the Absorb was not inferior to the Xience regarding TLF (the primary endpoint, $5.0 \%$ vs. $3.7 \%$; $p=0.02$ for non-inferiority, $p=0.11$ for superiority). A trend towards an increased risk of device thrombosis was reported for the Absorb ( $0.6 \%$ vs. $0.2 \% ; p=0.06)$. Interestingly, after the exclusion of patients with acute coronary syndromes (ABSORB III study-like population) the risk of device thrombosis dropped to $0.4 \%$ vs. $0.0 \%$ (Fig. 5 ). These results suggest that, compared to ABSORB III, reducing the number of very small vessels treated in ABSORB IV substantially reduced the device thrombosis for BRS, but also for the Xience stent.

Several meta-analyses were conducted to compare outcomes of the Absorb vs. the Xience stent. For instance, in a meta-analysis of 3738 patients from six trials (ABSORB China, ABSORB II, ABSORB III, ABSORB Japan, EVERBIO II, TROFI II) the rates of TVF, TLR, MI, and death at one year were comparable for patients treated with the Absorb and the Xience stent [27]. However, the risk of definite or probable device thrombosis was higher for the Absorb (odds ratio [OR] 1.99; 95\% confidence interval [Cl] 1.00-3.98; $p=0.05$ ) and even more pronounced between 1 and 30 days after implantation (OR 3.11; 95\% Cl 1.24-7.82; $p=0.02$ ) [27]. A patient-level, pooled meta-analysis of 3389 patients from four randomised studies (ABSORB China, ABSORB II, ABSORB III, ABSORB Japan) did not confirm these findings; the rates of TVF and device thrombosis at one year were comparable between groups [28]. On the other hand, the meta-analysis by Ali et al. [29] of two-year outcomes of 5583 patients from seven randomised trials showed a higher risk of TVF in patients treated with the Absorb (9.4\% vs. $7.4 \%$; $p=0.0059$; Fig. 3). This difference was driven by increased rates of target-vessel $\mathrm{MI}$ and ischaemia-driven TLR. Also, the two-year cumulative incidence of device thrombosis 
was higher for the Absorb than for the Xience stent $(2.3 \%$ vs. $0.7 \%$; $<<0.001)$. Interestingly, a landmark analysis between one and two years confirmed higher rates of TVF $(3.3 \%$ vs. $1.9 \% ; p=0.0376)$ and device thrombosis $(0.5 \%$ vs. $0.0 \%$; $p<0.001)$ in patients treated with the Absorb [29]. These findings were strengthened by a recent individual-patient-data pooled meta-analysis of 3389 patients from four ABSORB trials [30]. In this meta-analysis, implantation of the Absorb was associated with higher three-year rates of TVF $(11.7 \%$ vs. $8.1 \%$; $\mathrm{p}=0.006)$, target-vessel $\mathrm{MI}(7.8 \%$ vs. $4.2 \% ; \mathrm{p}=0.0006)$, and ischaemia-driven TLR (6.6\% vs. $4.4 \% ; p=0.02)$, with comparable cardiac mortality (1.1\% vs. $1.1 \% ; p=0.85$; Fig. 4). The risk of device thrombosis at three years was higher for BRS $(2.4 \%$ vs. $0.6 \% ; p=0.001)$. In addition, between one and three years, TVF $(6.1 \%$ vs. $3.9 \% ; p=0.02)$ and device thrombosis $(1.1 \%$ vs. $0.0 \% ; p<0.001)$ were higher for the Absorb [30]. A recent network meta-analysis by Kang et al. [31] provides some data on the indirect comparison of the long-term clinical performance of the Absorb in comparison to other metallic BMSs and DESs. This meta-analysis of 105,842 patients from 91 randomised controlled trials with a mean follow-up of 3.7 years concluded that patients treated with the Absorb had a significantly higher risk of definite or probable device thrombosis as compared to those treated with metallic DESs. Also, the risk of very late device thrombosis was highest with the Absorb among comparators. Interestingly, the risk of device thrombosis for BRS was higher than assumed from BMS and first-generation DES. However, this indirect evidence seems to be rather weak [31].

The results of the above-discussed studies suggest an increased and persistent risk of device thrombosis even at two to three years after scaffold implantation. This finding is somewhat contrary to the concept of vascular restoration with BRS, which was believed to be associated with improved long-term safety [9]. There are several possible factors suggested to be linked to this phenomenon. First, higher thrombogenicity might be observed with BRS, particularly in cases where a suboptimal deployment technique was used in combination with relatively large strut thickness of the scaffold. As confirmed by optical coherence tomography as well as an ex vivo animal model, the large strut thickness of the Absorb may induce local haemodynamic alterations leading to platelet activation and increased acute thrombogenicity. Second, thrombogenicity and local inflammation might be induced by the breakdown products and/or the extracellular matrix replacing the strut void [12, 32-34]. Third, similarly to metallic DES, incomplete lesion coverage, underexpansion, and strut malapposition were shown to be linked to the Absorb thrombosis [35-37]. However, these might be expected more frequently with the Absorb due to its physical properties and a higher possibility of acute recoil and strut fracture as compared to metallic DES. Also, specifically for BRS technologies, the loss of integrity of the scaffold backbone as a result of bioresorption may lead to prolapse of part of the scaffold into the vessel lumen and possible disturbances of coronary blood flow [12, 32-34, 37]. In addition, a recent substudy of the ABSORB EXTEND trial has suggested the occurrence and progression of in-scaffold neoatherosclerosis with luminal narrowing five years after Absorb scaffold implantation [38].

Importantly, the risk of thrombotic events after Absorb implantation may be diminished by proper patient and lesion selection, as well as the optimisation of scaffold implantation. For instance, the benefit of standardised implantation technique in the reduction of scaffold thrombosis was confirmed [39]. This standardised protocol included pre-dilation with noncompliant balloon up to the same size as the RVD, confirmation of proper vessel dilatation, implantation of the Absorb of the same size as the RVD at 10 to $12 \mathrm{~atm}$, and finally postdilatation with noncompliant balloons up to a maximum of $0.5 \mathrm{~mm}$ larger at 14 to $16 \mathrm{~atm}$. In addition, other studies have confirmed the impact of vessel sizing and operator technique on achieved outcomes after Absorb implantation [40-42]. Prolonged DAPT may limit the risk of scaffold thrombosis. However, the choice and duration of DAPT after BRS have not been clearly defined or tested in randomised studies [12]. A recent expert review suggests that DAPT should be continued for at least 12 months after BRS, with an option of prolongation up to 24 months and beyond in selected patients and lesions (i.e. complex lesions; > one BRS implanted; other unfavourable clinical, angiographic, and procedural characteristics) [43]. It should be considered if no significant bleeding issues arise during the first 12 months. Similarly, a report of the European Society of Cardiology-European Association of Percutaneous Cardiovascular Interventions (ESC-EAPCI) Task Force on the evaluation and use of BRS recommends prolongation of the DAPT for the expected duration of bioresorption for a given BRS (e.g. $\geq 36$ months after the Absorb) [12]. It is unknown whether the use of ticagrelor or prasugrel has a more protective effect against scaffold thrombosis than clopidogrel. However, it is obvious that patients who cannot tolerate or are unlikely to be compliant with extended-duration DAPT, including patients on oral anticoagulants, are not good candidates for BRS [12].

Another suggested benefit of BRS is the recovery of the vasomotor response, which is said to be associated with a lower incidence of angina and ischaemia under stress conditions. A detailed analysis of the ABSORB Cohort B study confirmed only a numerical increase of the vasomotor response to nitroglycerine after the Absorb scaffold implantation measured by mean lumen diameter. Importantly, the vasomotor response trended to moderately increase, which is consistent with the progressive degradation and bioresorption of the scaffold, but the degree of vasomotor response remained lower in comparison with adjacent segments [44]. Surprisingly, the same degree of vasomotion restoration and angina relief was confirmed for the Xience DES [45, 46]. 


\section{DESOLVE BIORESORBABLE SCAFFOLD}

The DESolve scaffold is a novolimus-eluting polymeric BRS, which received CE mark approval in May 2014 (Fig. 1D). The first generation of DESolve had $150-\mu \mathrm{m}$ strut thickness, and the currently available second generation, DESolve Cx PLUS, has $120-\mu \mathrm{m}$ struts [47]. The DESolve scaffold differs from the Absorb and other polymeric BRS scaffolds by its early degradation and resorption profile ( $>90 \%$ polymer degradation at six months and $\sim 70 \%$ polymer bioresorption at 12 months). The DESolve scaffold also provides a larger range of expansion and uniquely exhibits a self-correction feature, which can resolve minor malapposition to the vessel wall $[47,48]$. In a study involving 72 patients, wherein the acute mechanical performance of the DESolve scaffold was compared with the Absorb scaffold in terms of appropriate deployment with optical coherence tomography, the DESolve scaffold showed a trend towards a lower residual in-scaffold area stenosis and a larger maximum and minimum scaffold diameter [49]. So far, randomised clinical data on the head-to-head comparison of the DESolve with other BRSs or metallic DESs are not available. However, the propensity-score matching analysis suggested no differences in clinical performance of the Absorb vs. the DESolve BRS at one year (TVF $4.7 \%$ vs. $4.5 \% ; p=0.851$, definite device thrombosis $2.0 \%$ vs. $1.0 \% ; p=0.529$ ) [50]. The DESolve Nx clinical study involving 126 patients showed a high device and procedural success and low rates of adverse events, including low device thrombosis $(0.8 \%)$, through 24 months [51]. Serial intravascular ultrasound evaluation showed an increase in the device and lumen dimensions between baseline and six months, with no detectable footprints of the scaffold at 18 months [52]. Furthermore, in the DESolve PMCF study involving 102 patients with CAD, a low rate of TVF (3.0\%) and device thrombosis (1.0\%) was observed at 12 months [53]. Real-world data of the DESolve scaffold show high rates of successful scaffold implantations with low rates of periprocedural complications and major adverse cardiac events in long-term follow-up [54]. The initial experience with a new generation DESolve $\mathrm{Cx}$ has shown no ischaemic events and device thrombosis at 12 months after implantation [Abizaid et al., TCT 2017].

\section{FANTOM BIORESORBABLE SCAFFOLD}

The Fantom scaffold is a sirolimus-eluting BRS made principally from an iodinated polycarbonate copolymer of tyrosine analogues (desaminotyrosine) and biocompatible hydroxyesters (Fig. 1B) [55]. The CE mark approval for the device was granted in April 2017. Despite a strut thickness of $125 \mu \mathrm{m}$, the design and structural properties of the polymer afford radial strength comparable to or greater than contemporary metallic DESs, with low rates of recoil. In addition, unlike other available polymer BRSs, the Fantom consists of unique radiopaque polymer, which may facilitate device positioning. Moreover, this design allows rapid inflation during deployment similar to a metal stent. However, limited data are available on clinical outcomes after Fantom scaffold implantation. In the FANTOM II study (Cohort A) [55], a total of 117 patients with a single de novo lesion $\leq 20 \mathrm{~mm}$ and RVD 2.5 to $3.5 \mathrm{~mm}$ were enrolled. Binary restenosis was noted in $2.0 \%$ of patients. At six months, TVF occurred in $2.6 \%$ of patients and device thrombosis in $0.9 \%$ of patients. Initial results for 240 patients (FANTOM II study; Cohorts A and B) have shown a TVF rate of $4.2 \%$ and definite device thrombosis rate of $0.4 \%$ (single sub-acute thrombosis) at 12 months [Abizaid, EuroPCR 2017]. These excellent results were maintained for up to 24 months with TVF of 5.0\% and definite or probable scaffold thrombosis of 0.8\% [Abizaid, EuroPCR 2018]. Five-year follow-up is pending. A case example of a Fantom scaffold implantation is shown in Figure 6. In February 2018, the company achieved CE mark approval for a new generation device called Fantom Encore BRS, with 2.5-mm diameter and reduced strut profile $(95 \mu \mathrm{m})$.

\section{ART BIORESORBABLE SCAFFOLD}

The ART bioresorbable scaffold is made from a PDLLA amorphous polymer. It received CE mark approval in May 2015. Notably, the device does not contain an anti-proliferative drug. The lack of an anti-proliferative drug was suggested to be associated with early endothelial coverage of the ART BRS based on animal studies. This rapid degradation of the ART BRS might lead to reduced risk of late device thrombosis. However, this concept should be confirmed in further studies. So far, only one study (ARTDIVA) [Lafont, BRS 2014; Lafont, TCT 2016] reported clinical and angiographic outcomes of the ART BRS. In a group of 30 patients, at six months only one (3.3\%) ischaemia-driven TLR was reported.

\section{MAGMARIS BIORESORBABLE MAGNESIUM SCAFFOLD}

The Magmaris BRS, formerly known as DREAMS 2G, is the first sirolimus-eluting, bio-corrodible metallic BRS (Fig. 1C). It gained CE mark approval in June 2016. It is the successor to the paclitaxel-eluting DREAMS platform [56]. Thanks to its metallic alloy, Magmaris BRS is believed to have better lesion crossing, trackability, and pushability than polymeric BRSs. The DREAMS 2G was tested in the non-randomised BIOSOLVE-II study including 123 patients [57]. At six months, TLF was observed in $3.3 \%$ of patients, with $0.8 \%$ cardiac death, $0.8 \%$ periprocedural $\mathrm{MI}$, and $1.7 \%$ ischaemia-driven TLR [57]. These encouraging results were sustained for 12 months; no additional events were observed beyond the six-month follow-up [58, 59]. During the entire follow-up of 36 months none of the patients experienced a definite or probable scaffold thrombosis. The TLF rate at 36 months was $6.8 \%$. Similarly, in the initial cohort of 200 patients enrolled in the BIOSOLVE-IV study, $4.6 \%$ of patients experienced TLF and $0.5 \%$ had definite or probable scaffold thrombosis at 

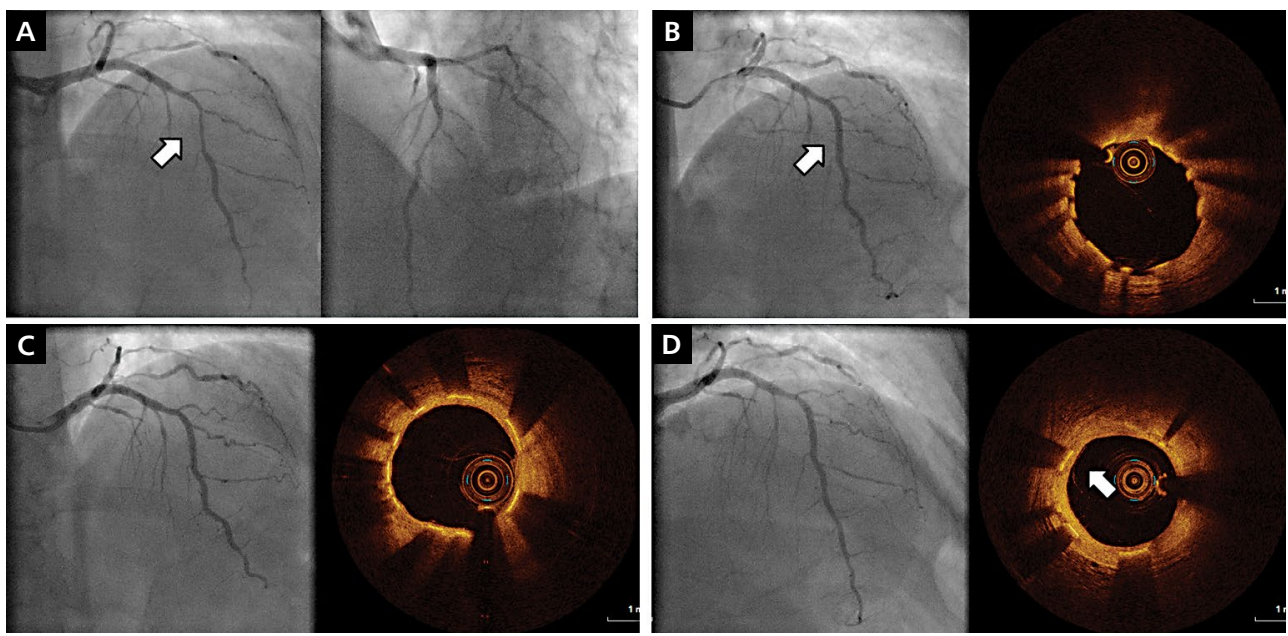

Figure 6. A case example of a 65-year-old female patient with stable angina treated with Fantom scaffold (the FANTOM II study); A. Baseline angiography with $80 \%$ stenosis of the left anterior descending artery (arrow) and an optimal result of the previous implantation of a metallic drug-eluting stent in the left circumflex artery; B. Final angiography and optical coherence tomography $(\mathrm{OCT})$ after successful implantation of the Fantom scaffold $3.0 \times 18 \mathrm{~mm}$ up to $14 \mathrm{~atm}$ and postdilatation with non-compliant balloon $3.25 \times 6 \mathrm{~mm}$ up to $16 \mathrm{~atm}$ (arrow); C. Six-month control angiography and OCT with a maintained optimal result of scaffold implantation; D. Two-year control angiography with a maintained optimal result of scaffold implantation. Complete coverage of the scaffold struts confirmed by OCT (arrow)

12 months after Magmaris BRS implantation [Lee, EuroPCR 2018]. Importantly, this single event of scaffold thrombosis occurred in a patient who terminated DAPT early (five days) after implantation. Serial intracoronary imaging following implantation of the Magmaris BRS confirmed restoration of the vessel geometry, vasomotion, and bioresorption signs for up to 12 months [60]. Importantly, these changes occurred with preservation of the lumen size between six and 12 months. Notably, in an animal model, neoatherosclerosis was significantly reduced with the Magmaris BRS as compared to a metallic stent with identical design, geometry, and drug coating [Joner, ESC 2017]. Thus, so far, magnesium-based scaffolds fulfil the main assumptions of vascular restoration therapy: support, resorption, and restoration. However, no randomised clinical trial results are available to date.

\section{OTHER DEVICES}

Apart from BRS technologies that are already CE-marked, several BRS devices are under clinical and preclinical investigation (Table 1). These include, but are not limited to, MeRes100 (Meril Life Sciences, India; Fig. 1F), Mirage (Manli Cardiology, Singapore; Fig. 1G), NeoVas (Lepu Medical Technology, China), Renuvia (Boston Scientific, MA, USA), Aptitude and Magnitude (Amaranth Medical, CA, USA), Xinsorb (HuaAn Biotechnology, UK), Firesorb (MicroPort, China), Unity (QualiMed, Germany; Fig. 1E), and Falcon (Abbott Vascular, CA, USA). Some of them have unique features. For instance, the Renuvia has increased over-expansion capability. This BRS uses a Synergy DES delivery system, which may allow for good deliverability and trackability of the device. This technology is already being tested in the RENUVIA FAST study. The main feature of the Mirage BRS is its helicoidal structure, which allows enhanced flexibility and low crossing profile. The radial strength of the device is comparable to other BRS and metallic stents. In addition, the mono-fibre circular struts of the Mirage were suggested to penetrate better into the vessel wall than the quadratic struts of other BRS and to cause less peri-strut shear stress and disturbance in the coronary blood flow [61]. A randomised study in 60 patients with CAD was conducted to assess outcomes of the Mirage vs. the Absorb BRS [62]. At 12 months, the median in-scaffold late luminal loss was comparable for the Mirage and the Absorb (0.37 vs. $0.23 \mathrm{~mm} ; \mathrm{p}=0.52$ ). However, angiographic median in-scaffold diameter stenosis was significantly higher for the Mirage (28.6\% vs. $18.2 \%$; $p=0.046$ ) [62]. No difference in clinical endpoints was observed (TLF: $17.2 \%$ vs. $14.8 \%$; $\mathrm{p}=0.73$ ), with a single (3.4\%) definite subacute device thrombosis in the Mirage group. The MeRes100 BRS has a hybrid cell design (closed cells at the edges and open cells along the length), which allows optimal vessel wall conformability and high radial strength. The couplets of tri-axial platinum radiopaque markers may facilitate the device positioning [63]. In the MeRes- 1 first-in-human trial 108 patients (116 lesions) were treated with the MeRes100. At six months, quantitative coronary angiography confirmed no binary restenosis, with in-scaffold late lumen loss of $0.15 \pm 0.23 \mathrm{~mm}$. The rate of TLF was $0.93 \%$ at 12 months and $1.87 \%$ at 24 months, with no events of device thrombosis [63] [Chandra, EuroPCR 
2018]. The Xinsorb is characterised by good deliverability and fast drug release ( $80 \%$ of drug eluted in 28 days ex vivo). Initial results for 30 patients showed encouraging results with in-scaffold late lumen loss of $0.17 \pm 0.12 \mathrm{~mm}$ and no device thrombosis at six months [64]. Recently presented results of the randomised XINSORB study [Ge, TCT 2017] have confirmed that the Xinsorb is not inferior to a biodegradable-polymer-based sirolimus-eluting stent (Tivoli stent) regarding peri-device late lumen loss (Xinorb vs. Tivoli: $0.19 \pm 0.32 \mathrm{~mm}$ vs. $0.31 \pm 0.41 \mathrm{~mm} ; \mathrm{p}<0.001)$ at one year. The rates of TLF and definite or probable device thrombosis for the Xinsorb at one year were $1.6 \%$ and $0.5 \%$, respectively. Similarly, a first-in-man study with the NeoVas has shown promising clinical and multimodality imaging results at six months, with no events of device thrombosis. In a head-to-head comparison with cobalt-chromium everolimus-eluting stent [65], the NeoVas proved to be less effective in terms of device success than metallic DES. On the other hand, the NeoVas was not inferior regarding in-scaffold late lumen loss at one year as compared to the control. The rates of TLF and device thrombosis were comparable between groups (NeoVas vs. control: TLF $4.3 \%$ vs. $3.5 \% ; p=0.64$, definite or probable device thrombosis $0.4 \%$ vs. $0.0 \% ; p=0.50$ ). The Unity BRS was initially developed as a biliary/peripheral vascular stent. However, performance of the device in coronary arteries is now being tested in animal models. Similarly to the Magmaris BRS, the Unity BRS consists of a magnesium core and polymer outer. Thus, its usability and mechanical properties seem to be comparable to regular metallic stents. Recently presented data from the RENASCENT II study with an Aptitude scaffold (115 $\mu \mathrm{m})$ and the RENASCENT III study with the Magnitude scaffold $(98 \mu \mathrm{m})$ have confirmed excellent device performance with no cases of device thrombosis [Chieffo, EuroPCR 2018]. The successor to these devices is going to be a new $85-\mu \mathrm{m}$ scaffold called Defiance. The Absorb technology is currently under refinement, and the next generation of the Absorb, referred to sometimes as the Falcon, is under preclinical testing. The new scaffold is expected to have thinner struts $(<100 \mu \mathrm{m})$, and improved deliverability and acute performance [11]

\section{RECOMMENDATIONS FOR THE USE AND EVALUATION OF BIORESORBABLE SCAFFOLDS}

Recently the ESC-EAPCI Task Force issued practical guidance on the evaluation and use of BRSs in patients with CAD undergoing PCl [12]. This deals mainly with the Absorb BRS because most of the clinical evidence comes from the ABSORB studies. The primary reason for such guidance was the higher than expected rate of very late device thrombosis reported for the Absorb BRS. Also, available evidence suggested no clear late advantage regarding clinical efficacy for the Absorb. Thus, the ESC-EAPCI Task Force concluded that BRS should not be preferred over current generation DESs in everyday clinical practice. Importantly, all on-going stud- ies should be thoroughly monitored for adverse events and achieved data should be published regularly. As mentioned before, BRS should not be recommended in patients who cannot tolerate prolonged DAPT or who require treatment with oral anticoagulants [12].

Apart from patient selection, proper lesion selection and preparation seems crucial to achieve optimal results of BRS implantation. According to the ESC-EAPCI Task Force document, the use of BRS is strongly discouraged in heavily calcified vessels $[12,66]$. Also, its use is not recommended in coronary arteries with RVD $<2.5 \mathrm{~mm}$. Operators should be strongly encouraged to use intracoronary imaging for lesion assessment. Also, lesions should be routinely predilated with noncompliant balloons with the size of the estimated RVD. In the case of non-complete balloon expansion, even after the use of plaque modification techniques, the implantation of BRS should be abandoned. If more than one BRS is required, excessive scaffold overlap should be avoided and preferably a device-to-device technique should be applied. In all cases, high-pressure postdilatation with a noncompliant balloon is recommended. The size of the balloon should not exceed $0.5 \mathrm{~mm}$ over the nominal diameter of the device [12].

To ensure the highest safety control level, the ESC-EAPCI Task Force recommends an evaluation plan for BRS [12]. The preclinical testing should include characterisation of the finished product and mechanical testing. Bench and in vivo testing in animal models should follow strict recommendations [12]. Importantly, the duration of follow-up should be sufficient to capture all relevant biological processes pertaining to stent safety. In addition, determination of BRS degradation products as well as drug concentrations in blood and major organs is required. The clinical part of the plan assumes pre-CE-mark phase and post-CE-mark phase. The former should include initial human feasibility studies with BRS based on intravascular imaging evaluation and angiographic follow-up (small-sized, selected patients) and a subsequent randomised trial based on surrogate endpoints (medium-sized, comparator device). The latter phase should include a large-scale, clinical, randomised trial with long-term (preferably five-year) follow-up. Importantly, such a trial should be powered to confirm superiority over the comparator.

\section{CONCLUSIONS}

Despite some expected benefits of BRS, none of the available data have confirmed the advantage of the first-generation BRS over the metallic DES. Thus, the current generations of BRS, especially the Absorb BRS, should not be preferred to conventional DES in everyday clinical practice. On the other hand, the concept of vascular restoration therapy with BRS should not be abandoned. Next generations of BRS should aim not only to improve the acute performance of the device but, above all, long-term safety. However, the improvement might be achieved not only by device refinement but also 
with a proper technique of implantation, intravascular imaging guidance, as well as careful patient and lesion selection. As recommended by the ESC-EAPCI Task Force, all new BRS devices should be thoroughly evaluated in preclinical and clinical studies with planned long-term follow-up. These studies may allow confirmation of the presence of other possible benefits of BRS, including recovery of vasomotion and improved vessel healing. Thus, we still have to wait for the next revolution in the field of $\mathrm{PCl}$. However, thanks to very encouraging long-term results with the FANTOM and MAGMARIS scaffolds, it is certain that the revolution will come.

\section{Conflict of interest: none declared}

\section{References}

1. Brophy J, Belisle P, Joseph L. Evidence for Use of Coronary Stents: A Hierarchical Bayesian Meta-Analysis. Ann Intern Med. 2003; 138(10): 777, doi: 10.7326/0003-4819-138-10-200305200-00005.

2. Stettler C, Wandel S, Allemann S, et al. Outcomes associated with drug-eluting and bare-metal stents: a collaborative network meta-analysis. Lancet. 2007; 370(9591): 937-948, doi: 10.1016/S01406736(07)61444-5, indexed in Pubmed: 17869634

3. Bangalore S, Kumar S, Fusaro M, et al. Short- and long-term outcomes with drug-eluting and bare-metal coronary stents: a mixed-treatment comparison analysis of 117762 patient-years of follow-up from randomized trials. Circulation. 2012; 125(23): 2873-2891, doi: 10.1161/CIRCULATIONAHA.112.097014, indexed in Pubmed: 22586281.

4. Bangalore S, Toklu B, Amoroso N, et al. Bare metal stents, durable polymer drug eluting stents, and biodegradable polymer drug eluting stents for coronary artery disease: mixed treatment comparison meta-analysis. BMJ. 2013; 347: f6625, indexed in Pubmed: 24212107.

5. Dangas GD, Serruys PW, Kereiakes DJ, et al. Meta-analysis of everolimus-eluting versus paclitaxel-eluting stents in coronary artery disease: final 3-year results of the SPIRIT clinical trials program (Clinical Evaluation of the Xience V Everolimus Eluting Coronary Stent System in the Treatment of Patients With De Novo Native Coronary Artery Lesions). JACC Cardiovasc Interv. 2013; 6(9): 914-922, doi: 10.1016/j.jcin.2013.05.005, indexed in Pubmed: 24050859.

6. Palmerini T, Biondi-Zoccai G, Della Riva D, et al. Clinical outcomes with bioabsorbable polymer- versus durable polymer-based drug-eluting and bare-metal stents: evidence from a comprehensive network meta-analysis. J Am Coll Cardiol. 2014; 63(4): 299-307, doi: 10.1016/j.jacc.2013.09.061, indexed in Pubmed: 24211507

7. Windecker S, Kolh P, Alfonso F, et al. 2014 ESC/EACTS Guidelines on myocardial revascularization: The Task Force on Myocardial Revascularization of the European Society of Cardiology (ESC) and the European Association for Cardio-Thoracic Surgery (EACTS) Developed with the special contribution of the European Association of Percutaneous Cardiovascular Interventions (EAPCI). Eur Heart J. 2014; 35(37): 2541-2619, doi: 10.1093/eurhearti/ehu278, indexed in Pubmed: 25173339.

8. Iqbal J, Onuma Y, Ormiston J, et al. Bioresorbable scaffolds: rationale, current status, challenges, and future. Eur Heart J. 2014; 35(12): 765-776, doi: 10.1093/eurheartj/eht542, indexed in Pubmed: 24366915.

9. Lesiak M, Araszkiewicz A. "Leaving nothing behind": is the bioresorbable vascular scaffold a new hope for patients with coronary artery disease? Postepy Kardiol Interwencyjnej. 2014; 10(4): 283-288, doi: 10.5114/pwki.2014.46940, indexed in Pubmed: 25489324.
10. Kereiakes DJ, Onuma Y, Serruys PW, et al. Bioresorbable vascular scaffolds for coronary revascularization. Circulation. 2016; 134(2): 168-182, doi: 10.1161/CIRCULATIONAHA.116.021539, indexed in Pubmed: 27400899.

11. Regazzoli D, Leone PP, Colombo A, et al. New generation bioresorbable scaffold technologies: an update on novel devices and clinical results. J Thorac Dis. 2017; 9(Suppl 9): S979-S985, doi: 10.21037/jtd.2017.07.104, indexed in Pubmed: 28894604.

12. Byrne RA, Stefanini GG, Capodanno D, et al. Report of an ESC-EAPCI Task Force on the evaluation and use of bioresorbable scaffolds for percutaneous coronary intervention: executive summary. EuroIntervention. 2018; 13(13): 1574-1586, doi: 10.4244/EIJ20170912-01, indexed in Pubmed: 28948934.

13. Reczuch K, Milewski K, Wąsek W, et al. [Bioresorbable scaffolds in the treatment of coronary artery disease. Expert consensus statement of the Association of Cardiovascular Interventions of the Polish Cardiac Society (ACVI PCS)]. Kardiol Pol. 2017; 75(8): 817-835, doi: 10.5603/KP.2017.0160, indexed in Pubmed: 28819961.

14. Capodanno D. Time for a debriefing: is there a future for bioresorbable scaffolds? EuroIntervention. 2018; 13(16): 1857-1859, doi: 10.4244/EIJV13I16A301, indexed in Pubmed: 29555614.

15. Serruys PW, Ormiston JA, Onuma Y, et al. A bioabsorbable everolimus-eluting coronary stent system (ABSORB): 2-year outcomes and results from multiple imaging methods. Lancet. 2009; 373(9667): 897-910, doi: 10.1016/S0140-6736(09)60325-1, indexed in Pubmed: 19286089.

16. Gutiérrez-Chico JL, Witt UE, Jaguszewski M. Off-label indications for bioresorbable scaffolds: "Beethoven can, but you cannot”. Adv Interv Cardiol. 2016; 12(1): 1-2, doi: 10.5114/pwki.2016.56941, indexed in Pubmed: 26966441.

17. Gil RJ, Bil J, Pawłowski T, et al. The use of bioresorbable vascular scaffold Absorb BVS ${ }^{\circledR}$ in patients with stable coronary artery disease: one-year results with special focus on the hybrid bioresorbable vascular scaffolds and drug eluting stents treatment. Kardiol Pol. 2016; 74(7): 627-633, doi: 10.5603/KP.a2015.0250, indexed in Pubmed: 26779846.

18. Dudek D, Rzeszutko Ł, Zasada W, et al. Bioresorbable vascular scaffolds in patients with acute coronary syndromes: the POLAR ACS study. Pol Arch Med Wewn. 2014; 124(12): 669-677, indexed in Pubmed: 25563622.

19. Rzeszutko Ł, Siudak Z, Tokarek T, et al. Twelve months clinical outcome after bioresorbable vascular scaffold implantation in patients with stable angina and acute coronary syndrome. Data from the Polish National Registry. Adv Interv Cardiol. 2016; 12(2): 108-115, doi: 10.5114/aic.2016.59360, indexed in Pubmed: 27279869 .

20. Rzeszutko Ł, Tokarek T, Siudak Z, et al. Patient profile and periprocedural outcomes of bioresorbable vascular scaffold implantation in comparison with drug-eluting and bare-metal stent implantation. Experience from ORPKI Polish National Registry 2014-2015. Adv Interv Cardiol. 2016; 12(4): 321-328, doi: 10.5114/aic.2016.63632, indexed in Pubmed: 27980545.

21. Vassilev D, Dosev L, Gil RJ. Is it possible to further improve clinical results with coronary bifurcation stenting, or what is more important - the technique or the stent? Kardiol Pol. 2017; 75(2): 91-100, doi: 10.5603/KP.2017.0024, indexed in Pubmed: 28205195.

22. Roleder T, Wanha W, Smolka G, et al. Bioresorbable vascular scaffolds in saphenous vein grafts (data from OCTOPUS registry). Postepy Kardiol Interwencyjnej. 2015; 11(4): 323-326, doi: 10.5114/pwki.2015.55604, indexed in Pubmed: 26677383.

23. Capodanno D, Gori T, Nef H, et al. Percutaneous coronary intervention with everolimus-eluting bioresorbable vascular scaffolds in routine clinical practice: early and midterm outcomes from the European multicentre GHOST-EU registry. EuroIntervention. 
2015; 10(10): 1144-1153, doi: 10.4244/EIJY14M07_11, indexed in Pubmed: 25042421.

24. Ellis SG, Kereiakes DJ, Metzger DC, et al. Everolimus-Eluting bioresorbable scaffolds for coronary artery disease. N Engl J Med. 2015; 373(20): 1905-1915, doi: 10.1056/NEJMoa1509038, indexed in Pubmed: 26457558.

25. Kereiakes DJ, Ellis SG, Metzger C, et al. 3-year clinical outcomes with everolimus-eluting bioresorbable coronary scaffolds: the ABSORBIII trial. J Am Coll Cardiol. 2017; 70(23): 2852-2862, doi: 10.1016/j.jacc.2017.10.010, indexed in Pubmed: 29100702.

26. Wykrzykowska J, Kraak R, Hofma S, et al. Bioresorbable Scaffolds versus Metallic Stents in Routine PCI. N Engl J Med. 2017; 376(24): 2319-2328, doi: 10.1056/nejmoa1614954.

27. Cassese S, Byrne RA, Ndrepepa G, et al. Everolimus-eluting bioresorbable vascular scaffolds versus everolimus-eluting metallic stents: a meta-analysis of randomised controlled trials. Lancet. 2016; 387(10018): 537-544, doi: 10.1016/S0140-6736(15)00979-4, indexed in Pubmed: 26597771.

28. Stone GW, Gao R, Kimura T, et al. 1-year outcomes with the Absorb bioresorbable scaffold in patients with coronary artery disease: a patient-level, pooled meta-analysis. Lancet. 2016; 387(10025): 1277-1289, doi: 10.1016/S0140-6736(15)01039-9, indexed in Pubmed: 26825231.

29. Ali ZA, Serruys PW, Kimura T, et al. 2-year outcomes with the Absorb bioresorbable scaffold for treatment of coronary artery disease: a systematic review and meta-analysis of seven randomised trials with an individual patient data substudy. Lancet. 2017; 390(10096): 760-772, doi: 10.1016/S0140-6736(17)31470-8, indexed in Pubmed: 28732815.

30. Ali ZA, Gao R, Kimura T, et al. Three-Year outcomes with the absorb bioresorbable scaffold: individual-patient-data meta-analysis from the ABSORB randomized trials. Circulation. 2018; 137(5): 464-479, doi: 10.1161/CIRCULATIONAHA.117.031843, indexed in Pubmed: 29089314.

31. Kang SH, Gogas BD, Jeon KH, et al. Long-term safety of bioresorbable scaffolds: insights from a network meta-analysis including 91 trials. EuroIntervention. 2018; 13(16): 1904-1913, doi: 10.4244/EIJ-D-17-00646, indexed in Pubmed: 29278353.

32. Onuma Y, Sotomi Y, Shiomi H, et al. Two-year clinical, angiographic, and serial optical coherence tomographic follow-up after implantation of an everolimus-eluting bioresorbable scaffold and an everolimus-eluting metallic stent: insights from the randomised ABSORB Japan trial. EuroIntervention. 2016; 12(9): 1090-1101, doi: 10.4244/EIJY16M09_01, indexed in Pubmed: 27597270.

33. Räber L, Brugaletta S, Yamaji K, et al. Very late scaffold thrombosis: intracoronary imaging and histopathological and spectroscopic findings. J Am Coll Cardiol. 2015; 66(17): 1901-1914, doi: 10.1016/j.jacc.2015.08.853, indexed in Pubmed: 26493663

34. Räber L, Onuma Y, Brugaletta S, et al. Arterial healing following primary PCI using the Absorb everolimus-eluting bioresorbable vascular scaffold (Absorb BVS) versus the durable polymer everolimus-eluting metallic stent (XIENCE) in patients with acute ST-elevation myocardial infarction: rationale and design of the randomised TROFI II study. EuroIntervention. 2016; 12(4): 482-489, doi: 10.4244/EIJY15M08_03, indexed in Pubmed: 26342471.

35. Dziewierz A, Siudak Z, Rakowski T, et al. The impact of multiple stent implantation in the infarct-related artery on one-year clinical outcomes of patients with ST-elevation myocardial infarction undergoing primary percutaneous coronary intervention. Data from the Polish NRDES Registry. Kardiol Pol. 2016; 74(8): 717-725, doi: 10.5603/KP.a2016.0020, indexed in Pubmed: 26898971.

36. Kerkmeijer LS, Tenekecioglu E, Wykrzykowska JJ. Stent thrombosis in patients with drugeluting stents and bioresorbable vascular scaffolds: the feared complication. Pol Arch Intern
Med. 2018; 128(1): 52-59, doi: 10.20452/pamw.4180, indexed in Pubmed: 29339714.

37. Sotomi Y, Suwannasom P, Serruys PW, et al. Possible mechanical causes of scaffold thrombosis: insights from case reports with intracoronary imaging. EuroIntervention. 2017; 12(14): 1747-1756, doi: 10.4244/EIJ-D-16-00471, indexed in Pubmed: 27773862.

38. Moriyama N, Shishido K, Tanaka Y, et al. Neoatherosclerosis 5 years after bioresorbable vascular scaffold implantation. J Am Coll Cardiol. 2018; 71(17): 1882-1893, doi: 10.1016/j. jacc.2018.02.051, indexed in Pubmed: 29699614.

39. Puricel S, Cuculi F, Weissner M, et al. Bioresorbable coronary scaffold thrombosis: multicenter comprehensive analysis of clinical presentation, mechanisms, and predictors. J Am Coll Cardiol. 2016; 67(8): 921-931, doi: 10.1016/j.jacc.2015.12.019, indexed in Pubmed: 26916481.

40. Ortega-Paz L, Capodanno D, Gori T, et al. Predilation, sizing and post-dilation scoring in patients undergoing everolimus-eluting bioresorbable scaffold implantation for prediction of cardiac adverse events: development and internal validation of the PSP score. EuroIntervention. 2017; 12(17): 2110-2117, doi: 10.4244/EIJ-D-16-00974, indexed in Pubmed: 28246060.

41. Serruys PW, Onuma Y. Dmax for sizing, PSP-1, PSP-2, PSP-3 or OCT guidance: interventionalist's jargon or indispensable implantation techniques for short- and long-term outcomes of Absorb BRS? EuroIntervention. 2017; 12(17): 2047-2056, doi: 10.4244/EIJY17M02 01, indexed in Pubmed: 28246059.

42. Yamaji K, Räber L, Windecker S. What determines long-term outcomes using fully bioresorbable scaffolds: the device, the operator or the lesion? EuroIntervention. 2017; 12(14): 1684-1687, doi: 10.4244/EIJV12I14A277, indexed in Pubmed: 28119252.

43. Capodanno D, Angiolillo DJ. Antiplatelet therapy after implantation of Bioresorbable vascular scaffolds: a review of the published data, practical recommendations, and future directions. JACC Cardiovasc Interv. 2017; 10(5): 425-437, doi: 10.1016/j.jcin.2016.12.279, indexed in Pubmed: 28279311.

44. Dudek D, Rzeszutko Ł, Onuma Y, et al. Vasomotor response to nitroglycerine over 5 years follow-up after everolimus-eluting bioresorbable scaffold implantation. JACC Cardiovasc Interv. 2017; 10(8): 786-795, doi: 10.1016/j.jcin.2016.12.020, indexed in Pubmed: 28427595.

45. Serruys PW, Chevalier B, Sotomi Y, et al. Comparison of an everolimus-eluting bioresorbable scaffold with an everolimus-eluting metallic stent for the treatment of coronary artery stenosis (ABSORB II): a 3 year, randomised, controlled, single-blind, multicentre clinical trial. Lancet. 2016; 388(10059): 2479-2491, doi: 10.1016/S01406736(16)32050-5, indexed in Pubmed: 27806897.

46. Capodanno D. Bioresorbable Scaffolds in Coronary Intervention: Unmet Needs and Evolution. Korean Circ J. 2018; 48(1): 24-35, doi: 10.4070/kcj.2017.0194, indexed in Pubmed: 29322695.

47. Mattesini A, Bartolini S, Sorini Dini C, et al. The DESolve novolimus bioresorbable Scaffold: from bench to bedside. J Thorac Dis. 2017; 9(Suppl 9): S950-S958, doi: 10.21037/jtd.2017.07.25, indexed in Pubmed: 28894601.

48. Nef HM, Wiebe J, Foin N, et al. A new novolimus-eluting bioresorbable coronary scaffold: Present status and future clinical perspectives. Int J Cardiol. 2017; 227: 127-133, doi: 10.1016/j. ijcard.2016.11.033, indexed in Pubmed: 27863289.

49. Mattesini A, Boeder N, Valente S, et al. Absorb vs. DESolve: an optical coherence tomography comparison of acute mechanical performances. EuroIntervention. 2016; 12(5): e566-e573, doi: 10.4244/EIJV12I5A96, indexed in Pubmed: 27497356.

50. Wiebe J, Dörr O, Ilstad H, et al. Everolimus- versus novolimus-eluting bioresorbable scaffolds for the treatment of coronary artery disease: a matched comparison. JACC Cardiovasc Interv. 2017; 10(5): 477-485, doi: 10.1016/j.jcin.2016.11.034, indexed in Pubmed: 28216214. 
51. Abizaid A, Costa RA, Schofer J, et al. Serial Multimodality Imaging and 2-Year Clinical Outcomes of the Novel DESolve Novolimus-Eluting Bioresorbable Coronary Scaffold System for the Treatment of Single De Novo Coronary Lesions. JACC Cardiovasc Interv. 2016; 9(6): 565-574, doi: 10.1016/j.jcin.2015.12.004, indexed in Pubmed: 27013155.

52. Barreira G, Costa JR, Costa R, et al. Serial intravascular ultrasound evaluation of the DESolve ${ }^{\mathrm{TM}}$ novolimus-eluting bioresorbable coronary scaffold system. Catheter Cardiovasc Interv. 2018 [Epub ahead of print], doi: 10.1002/ccd.27591, indexed in Pubmed: 29521477.

53. Nef H, Wiebe J, Boeder N, et al. A multicenter post-marketing evaluation of the Elixir DESolve Novolimus-eluting bioresorbable coronary scaffold system: First results from the DESolve PMCF study. Catheter Cardiovasc Interv. 2018 [Epub ahead of print], doi: 10.1002/ccd.27550, indexed in Pubmed: 29508518.

54. Gunes HM, Gokdeniz T, Kizilirmak Yilmaz F, et al. Real-life data regarding acute procedural success and 1-year clinical outcome of desolve bioresorbable scaffolds. J Interv Cardiol. 2017; 30(3): 189-194, doi: 10.1111/joic.12386, indexed in Pubmed: 28440067.

55. Abizaid A, Carrié D, Frey N, et al. 6-month clinical and angiographic outcomes of a novel radiopaque sirolimus-eluting bioresorbable vascular scaffold: the FANTOM II study. JACC Cardiovasc Interv. 2017; 10(18): 1832-1838, doi: 10.1016/j. jcin.2017.07.033, indexed in Pubmed: 28935075.

56. Rapetto C, Leoncini M. Magmaris: a new generation metallic sirolimus-eluting fully bioresorbable scaffold: present status and future perspectives. J Thorac Dis. 2017; 9(Suppl 9): S903-S913, doi: 10.21037/jtd.2017.06.34, indexed in Pubmed: 28894596.

57. Haude M, Ince H, Abizaid A, et al. Safety and performance of the second-generation drug-eluting absorbable metal scaffold in patients with de-novo coronary artery lesions (BIOSOLVE-II): 6 month results of a prospective, multicentre, non-randomised, first-in-man trial. Lancet. 2016; 387(10013): 31-39, doi: 10.1016/S0140-6736(15)00447-X, indexed in Pubmed: 26470647.

58. Haude M, Ince H, Abizaid A, et al. Sustained safety and performance of the second-generation drug-eluting absorbable metal scaffold in patients with de novo coronary lesions: 12-month clinical results and angiographic findings of the BIOSOLVE-II first-in-man trial. Eur Heart J. 2016; 37(35): 2701-2709, doi: 10.1093/eurheartj/ehw196, indexed in Pubmed: 27190094.

59. Haude M, Ince H, Kische S, et al. Sustained safety and clinical performance of a drug-eluting absorbable metal scaffold up to 24 months: pooled outcomes of BIOSOLVE-II and BIOSOLVE-III. EuroIntervention. 2017; 13(4): 432-439, doi: 10.4244/EIJ-D-17-00254, indexed in Pubmed: 28504239.

60. Garcia-Garcia HM, Haude M, Kuku K, et al. In vivo serial invasive imaging of the second-generation drug-eluting absorbable metal scaffold (Magmaris - DREAMS 2G) in de novo coronary lesions: Insights from the BIOSOLVE-II First-In-Man Trial. Int J Cardiol. 2018; 255: 22-28, doi: 10.1016/j.ijcard.2017.12.053, indexed in Pubmed: 29292064

61. Tenekecioglu E, Torii R, Sotomi Y, et al. The effect of strut protrusion on shear stress distribution: hemodynamic insights from a prospective clinical trial. JACC Cardiovasc Interv. 2017; 10(17): 1803-1805, doi: 10.1016/j.jcin.2017.06.020, indexed in Pubmed: 28882287.

62. Tenekecioglu E, Serruys PW, Onuma Y, et al. Randomized comparison of absorb bioresorbable vascular scaffold and mirage microfiber sirolimus-eluting scaffold using multimodality imaging. JACC Cardiovasc Interv. 2017; 10(11): 1115-1130, doi: 10.1016/j. jcin.2017.03.015, indexed in Pubmed: 28527768.

63. Seth A, Onuma Y, Costa R, et al. First-in-human evaluation of a novel poly-L-lactide based sirolimus-eluting bioresorbable vascular scaffold for the treatment of de novo native coronary artery lesions: MeRes-1 trial. EuroIntervention. 2017; 13(4): 415-423, doi: 10.4244/EIJ-D-17-00306, indexed in Pubmed: 28504218.

64. Wu Y, Shen Li, Ge L, et al. Six-month outcomes of the XINSORB bioresorbable sirolimus-eluting scaffold in treating single de novo lesions in human coronary artery. Catheter Cardiovasc Interv. 2016; 87 Suppl 1: 630-637, doi: 10.1002/ccd.26404, indexed in Pubmed: 26864162 .

65. Han Y, Xu Bo, Fu G, et al. A randomized trial comparing the neovas sirolimus-eluting bioresorbable scaffold and metallic everolimuseluting stents. JACC Cardiovasc Interv. 2018; 11(3): 260-272, doi: 10.1016/j.jcin.2017.09.037, indexed in Pubmed: 29413240.

66. Bartuś S, Januszek R, Legutko J, et al. Long-term effects of rotational atherectomy in patients with heavy calcified coronary artery lesions: a single-centre experience. Kardiol Pol. 2017; 75(6): 564-572, doi: 10.5603/KP.a2017.0042, indexed in Pubmed: 28631258.

Cite this article as: Dziewierz A, Dudek D. Current perspectives on the role of bioresorbable scaffolds in the management of coronary artery disease. Kardiol Pol. 2018; 76(7): 1043-1054, doi: 10.5603/KP.a2018.0130. 